\title{
ASSESSMENT OF UNDERGRADUATE MEDICAL STUDENTS USING OBJECTIVE STRUCTURED CLINICAL EXAMINATION IN GENERAL MEDICINE: STUDENT'S AND TEACHER'S PERCEPTION
}

\author{
Sudhir Kumar', Ashis Ranjan2, Govind Kumar 3 , Amit Mishra ${ }^{4}$, D. Barat ${ }^{5}$ \\ ${ }^{1}$ Associate Professor, Department of General Medicine, Indira Gandhi Institute of Medical Sciences, Patna. \\ ${ }^{2}$ Senior Resident, Department of General Medicine, Indira Gandhi Institute of Medical Sciences, Patna. \\ ${ }^{3}$ Associate Professor, Department of General Medicine, Indira Gandhi Institute of Medical Sciences, Patna. \\ ${ }^{4}$ Assistant Professor, Department of General Medicine, Indira Gandhi Institute of Medical Sciences, Patna. \\ 5 Professor \& HOD, Department of General Medicine, Indira Gandhi Institute of Medical Sciences, Patna.
}

ABSTRACT

\section{BACKGROUND}

Objective Structured Clinical Examinations (OSCEs) have become one of the most widely used methods of assessing aspects of clinical competency in healthcare education. Objective Structured Clinical Examinations (OSCEs) is also introduced in our newly formed medical college Indira Gandhi Institute of Medical Sciences (IGIMS), Patna, for last few years in different departments, but this is first study to know the perception of this evaluation method among students and faculties.

\section{AIM AND OBJECTIVE}

The aim of this study was to introduce the newer method of assessment Objective Structured Clinical Examinations (OSCEs). Objective of the study is to assess the perceptions of teachers and students regarding OSCE in general medicine.

\section{METHODOLOGY}

After obtaining permission from ethics committee, this cross-sectional study was conducted in Department of General Medicine; 84 students and 9 faculty members were briefed about OSCEs. At the end of $8^{\text {th }}$ semester, OSCE was conducted and immediate feedback regarding this method of examination was taken using Likert's scale. Perceptions of students and teachers were collected with suitable statements. Their suggestions and remarks were also collected.

\section{RESULTS}

A 55.55\% of faculty members agreed that OSCE covered a wide range of knowledge compared with conventional examination; $66 \%$ of faculty members agreed that OSCE assessed the various domain of student's knowledge in a better way compared with conventional examination; 88\% of teachers agreed that checklist in OSCE provided a fair system of marking which removed variability of examiner; 84 out of 87 students of $8^{\text {th }}$ semester undergraduate answered the questionnaire based on Likert's scale; $67 \%$ students strongly agreed that OSCE was a fair method of assessment compared with conventional examination; 58\% students found that OSCE tested a wide range of knowledge compared with conventional method. They were disagreed about OSCE being stressful and exhausting; 95\% students agreed about OSCE was a better way to assess the different aspect of knowledge and it should be followed as method of clinical assessment in General Medicine in coming internal examinations.

\section{KEYWORDS}

OSCEs: Objective Structured Clinical Examinations, OSPE: Objective Structured Practical Examination. Likert's Scale.

HOW TO CITE THIS ARTICLE: Sudhir Kumar, Ashis Ranjan, Govind Kumar, Amit Mishra, D. Barat. "Assessment of Undergraduate Medical Students Using Objective Structured Clinical Examination in General Medicine: Student's and Teacher's Perception." Journal of Evolution of Medical and Dental Sciences 2015; Vol. 4, Issue 99, December 10; Page: 16481-16484, DOI: $10.14260 /$ jemds/2015/2447

\section{INTRODUCTION}

The assessment of clinical learning is important in general medicine. The Medical Council of India emphasizes the importance of accurately assessing the competency of medical students.[1] Miller provides a conceptual framework for assessing clinical competency.[2] Miller's pyramid of clinical competency consists of "Know" and "Know how" at base and "Show how" and "Does" at apex. The traditional tools for assessment of medical students have mainly consists of written exams, bedside viva and clinical case presentation. To obviate the drawback of conventional clinical evaluation, OSCE was first introduced by Harden in 1975, as a more objective, valid and reliable tool of assessment. [3]

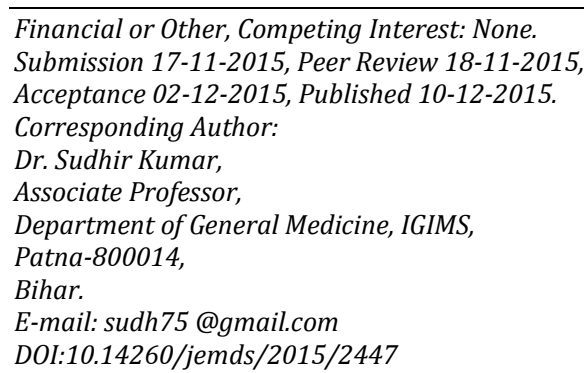

Objective Structured Clinical Examinations (OSCEs) have become one of the most widely used methods of assessing aspects of clinical competency in healthcare education. This method of assessment was originally developed in order to address the unreliability and lack of general ability of traditional forms of clinical assessment, such as the long case. $\left.{ }^{4]}\right]$ The overarching philosophy in OSCEs is that all candidates are presented with the same clinical tasks to be completed in the same timeframe and are scored using structured marking schemes. Compared to the long case, OSCEs reduce bias relating to the type of clinical case selected and who performs the assessment. Ideally, the only variance in an OSCE should be the candidate's performance. Objective structured clinical examination is meant to test the "Show how" level of Miller's pyramid. ${ }^{[4]}$ Objective structured clinical examination has been by and large used as an assessment tool for formative assessment of undergraduate medical students at few centres.[5,6,7]

\section{AIM AND OBJECTIVE}

The aim of this study was to introduce the newer method of assessment Objective Structured Clinical Examinations (OSCEs), which can assess the student's all three domain, i.e. cognitive, psycho-motor and affective. 
The objective of this study was to assess the perception of the students and faculty members about Objective Structured Clinical Examinations (OSCEs) in General Medicine.

\section{METHODOLOGY}

After obtaining permission from ethics committee, this crosssectional study was conducted in Department of General Medicine.

\section{Type of Study}

Cross-Sectional.

\section{Study Setting}

Department of General Medicine, IGIMS Medical College, Patna.

\section{Study Population}

All $8^{\text {th }}$ semester students and teachers of Department of General Medicine.

\section{Period of Study}

4 months.

\section{Inclusion Criteria}

Willing to participate in study.

\section{Exclusion Criteria}

Not willing to participate in study.

The teachers of General Medicine Department were briefed and sensitized through powerpoint presentation about the concepts of OSCE and then they were invited for intervention. Similarly, the $8^{\text {th }}$ semester students were briefed and sensitized about OSCE. With the help of faculties and residents of General Medicine Department, various stations were decided for OSCE examinations. At the end of $8^{\text {th }}$ semester, OSCE was conducted with 8 stations. Some important Stations were following:

1. Elicit the plantar reflex in patient.

2. Measure the liver span of patient.

3. Examine for pulse deficit and write the pulse deficit of patient.

4. Percuss the traube space.

5. Elicit the shifting dullness in patient.

6. Comment on facie of the patient.

Immediate feedback regarding this method of examination was taken. Perceptions of students and teachers were collected with suitable statements. Their suggestions and remarks were also collected.

\section{RESULTS}

The views and perceptions of teachers and students were noted with the help of Performa containing related statements. Performa was separate for teachers and students. Likert's scale was applied to know their degree of agreement with the statements. The present study was conducted in 84 students of 8th semester and the 9 teachers of Department of General Medicine, IGIMS, Patna. The study aimed to know the perceptions of the teachers and students regarding OSCE. Table 1 and Table 2 shows the perspectives of teachers and students respectively. However, they were also asked to mention any advantages, disadvantages as well as give some suggestion for making this examination more effective as mentioned below.

\section{Faculty Feedback: (Based on Likert's Scale) Table -1}

All 9 faculty members of Department of General Medicine $(100 \%)$ answered the questionnaire based on Likert's scale. (Table-1).

A $55.55 \%$ of faculty members agreed that OSCE covered a wide range of knowledge compared with conventional examination. A $66 \%$ of teachers agreed that OSCE compelled the students to learn different procedures in details. A $44 \%$ of teachers agreed that OSCE specifically highlighted the weak and strong part of subject. A $66 \%$ of faculty members agreed that OSCE assessed the various domain of student's knowledge in a better way compared with conventional examination. An $88 \%$ of teachers agreed that checklist in OSCE provided a fair system of marking, which removed variability of examiner. A $44 \%$ of teachers agreed that OSCE was exhausting and lengthy compared with conventional examination.

A $33 \%$ of teachers found OSCE is more stressful compared with conventional examination. But overall $88 \%$ of faculty member found that OSCE should be followed as method of assessment in General Medicine in all coming internal examinations.

\section{Advantages of OSCE according to faculty members}

1. Improves clinical skills and knowledge of students.

2. Help to improve teaching-learning process.

3. Students will learn clinical skills required.

Disadvantage of OSCE according to faculty members

1. Comprehensive assessment may not be possible as we have to follow Performa.

2. Only specific questions are to be asked as in Performa.

3. Preparation of stations requires expenses and time; continuous process.

4. A pattern of questions may be formed and students will study only concerned topics.

5. More resources (Examiners, time) required for preparation.

Suggestions by teachers to make OSCE more effective

1. Examiners should get a chance to ask questions related to stations, which are not there in Performa.

2. Teaching and assessment should go hand in hand.

3. Some modifications should be done in OSCE and can be implemented (OSCE+Traditional Practical Examination).

Higher level of OSCE should be conducted for student with distinction.

Student Feedback: (Based on Likert's scale) (Table-2)

An 84 out of 87 students of $8^{\text {th }}$ semester undergraduate answered the questionnaire based on Likert's scale. A $67 \%$ students strongly agreed that OSCE was a fair method of assessment compared with conventional examination. A 58\% students found that OSCE tested a wide range of knowledge compared with conventional method. They were disagreed about OSCE being stressful and exhausting. A 95\% students agreed about OSCE was a better way to assess the different aspect of knowledge and it should be followed as method of clinical assessment in General Medicine in coming internal examinations.

\section{Advantages of OSCE according to Students}

1. Attitude of examiners is better as compared to traditional practical examination students.

2. More conceptual learning.

3. No bias in time and questions by examiners.

4. Improves clinical skills, knowledge and self-confidence of students.

5. Feedback given by examiners, which was very helpful.

Disadvantages of OSCE according to Students

1. No direct interaction with examiners.

2. Little difficult to manage time at stations.

3. May not be comprehensive assessment.

Suggestions by Students to make OSCE more Effective

1. There should be some interaction or conversation with the examiners.

2. More time needed for each station. 
3. More emphasis should be given on maintaining confidentiality of the examination.

\section{DISCUSSION}

It is well known that conventional practical examination has several problems.[11-13] The traditional tools for assessment of medical students have mainly consisted of written exams (Essay type, multiple choice and short-answer type questions), bedside viva and clinical case presentation.

These have focused on the "Knows" and "Knows how" aspects, i.e., the focus has been on the base of the "Miller's pyramid of competence." Oral/viva examinations has been replaced by objective structured clinical examination to overcome the problems, which are faced in traditional practical examination in medical institutions. ${ }^{[10]}$ In one study Wadde SK, et al. found that both students and teachers accepted that OSCE is better than traditional practical examination. ${ }^{[8]}$ It can also be used to measure pre-clinical skills that other test do not perform.[9]

This particular study was aimed to understand the acceptability of the OSCE among students and teachers, as it was a relatively new assessment tool for them in our newly formed college. This experience provided an opportunity to know the student's and teacher's responses about OSCE. They raised some issues about advantages and disadvantages of this method of examination and also gave some suggestions for further improvement of OSCE. Both students and teachers accepted that this type of examination is better than the traditional practical examination.

The majority of students perceived that OSCE had a better content and construct validity since the OSCE, in its structured checklist pattern helped them navigate smoothly through the clinical steps thus helping them know their weaknesses in clinical examination making OSCE a better examination method and a learning stimulus compared with the traditional clinical examination.[14] Regarding the content of the OSCE, they felt that the questions were more relevant and logical with proper blueprinting of syllabus, the sequence of questions in the unobserved stations following the observed stations were proper and valid. Since all the students were exposed to similar types of questions with the same difficulty level, they felt that the checklist system is a fair and unbiased method with lesser element of luck playing any part in assessment. This also stimulated the critical thinking ability of the students, which was welcomed by the students. Similar views were put forward by Duffield.[15]

A $55.55 \%$ of faculty members agreed that OSCE covered a wide range of knowledge compared with conventional examination. A $66 \%$ of teachers agreed that OSCE compelled the students to learn different procedures in details. A $44 \%$ of teachers agreed that OSCE specifically highlighted the weak and strong part of subject. A $66 \%$ of faculty members agreed that OSCE assessed the various domain of student's knowledge in a better way compared with conventional examination. An $88 \%$ of teachers agreed that checklist in OSCE provided a fair system of marking, which removed variability of examiner. A $44 \%$ of teachers agreed that OSCE was exhausting and lengthy compared with conventional examination. A 33\% of teachers found OSCE is more stressful compared with conventional examination. But overall 88\% of faculty member found that OSCE should be followed as method of assessment in General Medicine in all coming internal examinations.

Regarding traditional university examination the teachers complained about extensiveness, but students complained about variability and irrelevance of questions by examiners. Most of the students and teachers agreed that examiner bias may be eliminated by following this type of assessment. They also agreed that it is easier to pass OSCE as compared to traditional practical examination. Several studies have proved the Objective Structured Clinical/Practical Examination as a reliable assessment tool.[16-19] The examiners should be involved in teaching a skill prior to assess it, which may be helpful in enhancing the quality of OSCE/OSPE. The examiners or assessors should be trained to ensure reliability and consistency in scoring criteria.[20,21]

\section{LIMITATIONS}

There are some limitations of this study like small sample size and a specific cohort selected from a medical institution, which restricts the generalization of results. Also, we could not cover the long-term impact of this methodology.

\section{CONCLUSION}

OSCE/OSPE ensures evaluation of set of predetermined clinical competencies. Each clinical competency is broken down into smaller components; e.g., taking history, performing examination, interpreting investigations, communicating, etc. Each component is assessed in turn and marks are allotted according to predetermined checklists. Most of the students and teachers agreed that examiner bias may be eliminated by following this type of assessment.

All the participants in the study were in favour of using this assessment method in future. OSCE/OSPE can provide a valid and reliable means of assessing the clinical skills of students.

\section{REFERENCES}

1. MCI regulation of graduate medical education 2012 (9.4.4).

2. Miller GE. The assessment of clinical skills/competence/performance. Acad Med 1990; 65 (9):563-7.

3. Harden RM, Stevenson W, Downie WW, et al Assessment of clinical competence using an objective structural clinical examination. Br Med J 1975;1:447-51.

4. Harden RM, Gleeson FA. Assessment of clinical competence using an objective structural clinical examination. Med Edu 1979;13:41-54.

5. Gupta P, Brisht HJ. A practical approach to running and objective structured clinical examination in neonatology for the formative assessment of undergraduate students. Indian Pediatrics 2001;38:500-13.

6. Verma M, Singh T. Attitude of medical students towards objective structured clinical examination in paediatrics. Indian Pediatrics 1993;30:1259-61.

7. Mathews L, Menon J, Mani NS. Micro OSCE for assessment of undergraduates. Indian Pediatrics 2004;41:159-63.

8. Wadde SK, Deshpande RH, Madole MB, et al. Assessment of 3rd MBBS Students using OSPE/OSCE in community medicine: Teachers and student perception. Sch j app med sci 2013;1(4):348-53.

9. Turner JL, MD; Donkoski ME. Objective Structured Clinical Exams: A Critical Review. Fam Med 2008;40(8):574-578.

10. Qureshi GS, Parveen S, Yasmin T. Objective Structured Practical Examination (OSPE): An experience at Dow University of Health Sciences (DUHS), Karachi. Medical channel. 2012;18(1)5-8.

11. Edlestein DR, Ruder HJ; Assessment of clinical skills using video tapes of the complete medical interview and physical examination. Med Teach. 1990;12:155-162.

12. Stiliman PL, Brown DR, Redfield DL, et al. Construct validation of the Arizona clinical interview rating scale. Education and Psychological Measurement, 1977;37:1031-1038. 
13. Newbie DI; The observed long case in clinical assessment. Medical Education, 1991;25:369-373.

14. Newbie DI. Eight years' experience with a structured clinical examination. Med Educ 1988;22(3):200-4.

15. Duffield KE, Spencer JA. A survey of medical student's views about the purposes and fairness of assessment. Med Educ 2002;36(9):879-86.

16. Lowry S; Assessment of students. British Medical Journal, 1993;306(6869):51-54.

17. Smee S; Skill based assessment. British Medical Journal, 2003;326(7391):703- 706.

18. Rushforth HE; Objective Structured Clinical Examination (OSCE): Review of literature and implications for nursing education. Nurse Education Today, 2006;27:481-490.
19. Oberle B and Muma R; the OSCE compared to the PACKRAT as a predictor of performance on the PANCE. Proc 4th Annual GRASP symposium, Wichita State University, 2008.

20. Harden R and Gleeson F; Assessment of clinical competence using an objective structured clinical examination. Medical Education. 1979;13:41-54.

21. Rennie A, Main M; Student midwives' views of the objective structured clinical examination. British Journal of Midwifery, 2006;14(10):602-607.

\begin{tabular}{|c|c|c|c|c|c|c|}
\hline $\begin{array}{l}\text { Sl. } \\
\text { No. }\end{array}$ & QUESTIONS & $\begin{array}{l}\text { STRONGLY } \\
\text { AGREE }\end{array}$ & AGREE & $\begin{array}{c}\text { NEITHER } \\
\text { AGREE } \\
\text { NOR } \\
\text { DISAGREE }\end{array}$ & DISAGREE & $\begin{array}{l}\text { STRONGLY } \\
\text { DISAGREE }\end{array}$ \\
\hline 1. & $\begin{array}{c}\text { OSCE covers a wide range of knowledge compared with } \\
\text { conventional examination }\end{array}$ & $\begin{array}{c}2 \\
(22.22 \%) \\
\end{array}$ & $\begin{array}{c}5 \\
(55.55 \%) \\
\end{array}$ & $\begin{array}{c}2 \\
(22.22 \%) \\
\end{array}$ & 0 & 0 \\
\hline 2. & $\begin{array}{l}\text { OSCE compels the students to learn different procedures } \\
\text { in detail }\end{array}$ & $\begin{array}{c}2 \\
(22.22 \%)\end{array}$ & $\begin{array}{c}6 \\
(66.66 \%) \\
\end{array}$ & $\begin{array}{c}1 \\
(11.11 \%)\end{array}$ & 0 & 0 \\
\hline 3. & $\begin{array}{l}\text { OSCE specifically highlights the weak and strong part of } \\
\text { subject }\end{array}$ & $\begin{array}{c}2 \\
(22.22 \%) \\
\end{array}$ & $\begin{array}{c}4 \\
(44.44 \%) \\
\end{array}$ & $\begin{array}{c}2 \\
(22.22 \%) \\
\end{array}$ & $\begin{array}{c}1 \\
(11.11 \%) \\
\end{array}$ & 0 \\
\hline 4. & $\begin{array}{l}\text { OSCE is more stressful compared with conventional } \\
\text { examination }\end{array}$ & 0 & $\begin{array}{c}3 \\
(33.33 \%) \\
\end{array}$ & $\begin{array}{c}1 \\
(11.11 \%) \\
\end{array}$ & $\begin{array}{c}5 \\
(55.55 \%) \\
\end{array}$ & 0 \\
\hline 5. & $\begin{array}{c}\text { OSCE is exhausting and lengthy compared with } \\
\text { conventional examination }\end{array}$ & 0 & $\begin{array}{c}4 \\
(44.44 \%)\end{array}$ & $\begin{array}{c}1 \\
(11.11 \%)\end{array}$ & $\begin{array}{c}4 \\
(44.44 \%)\end{array}$ & 0 \\
\hline 6. & $\begin{array}{l}\text { OSCE assesses the various domain of student's knowledge } \\
\text { in better way compared with conventional examination }\end{array}$ & $\begin{array}{c}1 \\
(11.11 \%) \\
\end{array}$ & $\begin{array}{c}6 \\
(66.66 \%) \\
\end{array}$ & $\begin{array}{c}1 \\
(11.11 \%) \\
\end{array}$ & $\begin{array}{c}1 \\
(11.11 \%) \\
\end{array}$ & 0 \\
\hline 7. & Checklist in OSCE provides a fair system of marking & 0 & $\begin{array}{c}8 \\
(88.88 \%) \\
\end{array}$ & 0 & $\begin{array}{c}1 \\
(11.12 \%) \\
\end{array}$ & 0 \\
\hline 8. & $\begin{array}{l}\text { Variability of examiner can be removed in better way by } \\
\text { OSCE }\end{array}$ & 0 & $\begin{array}{c}8 \\
(88.88 \%) \\
\end{array}$ & $\begin{array}{c}1 \\
(11.12 \%) \\
\end{array}$ & 0 & 0 \\
\hline 9. & OSCE may lead to change in bed-side teaching pattern & $\begin{array}{c}1 \\
(11.11 \%) \\
\end{array}$ & $\begin{array}{c}4 \\
(44.44 \%) \\
\end{array}$ & $\begin{array}{c}2 \\
(22.22 \%) \\
\end{array}$ & $\begin{array}{c}2 \\
(22.22 \%) \\
\end{array}$ & 0 \\
\hline 10. & $\begin{array}{l}\text { OSCE should be followed as method of assessment in } \\
\text { General Medicine in all coming internal examinations }\end{array}$ & $\begin{array}{c}1 \\
(11.11 \%)\end{array}$ & $\begin{array}{c}8 \\
(88.88 \%) \\
\end{array}$ & 0 & 0 & 0 \\
\hline
\end{tabular}

\begin{tabular}{|c|c|c|c|c|c|c|}
\hline $\begin{array}{l}\text { Sl. } \\
\text { No. }\end{array}$ & QUESTIONS & $\begin{array}{l}\text { STRONGLY } \\
\text { AGREE }\end{array}$ & AGREE & $\begin{array}{c}\text { NEITHER } \\
\text { AGREE } \\
\text { NOR } \\
\text { DISAGREE } \\
\end{array}$ & DISAGREE & $\begin{array}{l}\text { STRONGLY } \\
\text { DISAGREE }\end{array}$ \\
\hline 1. & $\begin{array}{c}\text { OSCE is fair method of assessment compared with } \\
\text { conventional examination }\end{array}$ & $\begin{array}{c}57 \\
(67.86 \%) \\
\end{array}$ & $\begin{array}{c}25 \\
(29.76 \%) \\
\end{array}$ & $\begin{array}{c}1 \\
(1.2 \%)\end{array}$ & $\begin{array}{c}1 \\
(1.2 \%) \\
\end{array}$ & 0 \\
\hline 2. & $\begin{array}{l}\text { OSCE test a wide range of knowledge compared with } \\
\text { conventional method }\end{array}$ & $\begin{array}{c}49 \\
(58.33 \%) \\
\end{array}$ & $\begin{array}{c}35 \\
(41.66 \%) \\
\end{array}$ & 0 & 0 & 0 \\
\hline 3. & $\begin{array}{l}\text { OSCE is easier to pass out compared with conventional } \\
\text { method }\end{array}$ & $\begin{array}{c}24 \\
(28.57 \%) \\
\end{array}$ & $\begin{array}{c}28 \\
(33.33 \%) \\
\end{array}$ & $\begin{array}{c}25 \\
(29.76 \%) \\
\end{array}$ & $\begin{array}{c}7 \\
(8.33 \%) \\
\end{array}$ & 0 \\
\hline 4. & $\begin{array}{l}\text { OSCE is more stressful compared with conventional } \\
\text { method }\end{array}$ & $\begin{array}{c}3 \\
(3.57 \%) \\
\end{array}$ & $\begin{array}{c}10 \\
(11.90 \%)\end{array}$ & $\begin{array}{c}19 \\
(22.61 \%)\end{array}$ & $\begin{array}{c}44 \\
(52.38 \%)\end{array}$ & $\begin{array}{c}8 \\
(9.52 \%) \\
\end{array}$ \\
\hline 5. & $\begin{array}{l}\text { OSCE is more exhausting compared with conventional } \\
\text { method }\end{array}$ & $\begin{array}{c}3 \\
(3.57 \%)\end{array}$ & $\begin{array}{c}2 \\
(2.38 \%)\end{array}$ & $\begin{array}{c}7 \\
(8.33 \%)\end{array}$ & $\begin{array}{c}61 \\
(72.61)\end{array}$ & $\begin{array}{c}11 \\
(13.09 \%)\end{array}$ \\
\hline 6. & $\begin{array}{l}\text { Observer's attitude during OSCE was better compared } \\
\text { with conventional method }\end{array}$ & $\begin{array}{c}40 \\
(47.61 \%) \\
\end{array}$ & $\begin{array}{c}37 \\
(44.04 \%) \\
\end{array}$ & $\begin{array}{c}6 \\
(7.14 \%) \\
\end{array}$ & $\begin{array}{c}1 \\
(1.2 \%)\end{array}$ & 0 \\
\hline 7. & $\begin{array}{l}\text { OSCE with simulator or standardized patient is better than } \\
\text { real patient }\end{array}$ & $\begin{array}{c}24 \\
(28.57 \%)\end{array}$ & $\begin{array}{c}21 \\
(25.00 \%)\end{array}$ & $\begin{array}{c}17 \\
(20.33 \%)\end{array}$ & $\begin{array}{c}17 \\
(20.33 \%) \\
\end{array}$ & $\begin{array}{c}4 \\
(4.76 \%)\end{array}$ \\
\hline 8. & OSCE may influence the learning pattern & $\begin{array}{c}44 \\
(52.38 \%)\end{array}$ & $\begin{array}{c}32 \\
(38.09 \%)\end{array}$ & $\begin{array}{c}6 \\
(7.14 \%) \\
\end{array}$ & $\begin{array}{c}2 \\
(2.40 \%)\end{array}$ & 0 \\
\hline 9. & $\begin{array}{l}\text { OSCE is a better way to assess the different aspect of } \\
\text { knowledge }\end{array}$ & $\begin{array}{c}39 \\
(46.42 \%)\end{array}$ & $\begin{array}{c}42 \\
(50.00 \%)\end{array}$ & $\begin{array}{c}3 \\
(3.57 \%)\end{array}$ & 0 & 0 \\
\hline 10. & $\begin{array}{l}\text { OSCE should be followed as method of assessment in } \\
\text { General Medicine in coming internal examinations. }\end{array}$ & $\begin{array}{c}47 \\
(55.98 \%)\end{array}$ & $\begin{array}{c}35 \\
(41.66 \%)\end{array}$ & $\begin{array}{c}2 \\
(2.4 \%)\end{array}$ & 0 & 0 \\
\hline
\end{tabular}

